\title{
PRODUCTION OF SUB-MICRO SIZED SILVER PARTICLES BY \\ CHEMICAL REDUCTION METHOD IN AN ENVIRONMENTALLY-FRIENDLY MANNER
}

\author{
Stevan Dimitrijević ${ }^{1 *}$, Michele Miliciani ${ }^{2}$, Silvana Dimitrijević ${ }^{3}$, \\ Milisav Ranitovićl, Željko Kamberović ${ }^{4}$ \\ ${ }^{1}$ University of Belgrade, Innovation Center of Faculty of Technology and Metallurgy, \\ Belgrade, Serbia, Karnegijeva 4, Belgrade, Serbia \\ ${ }^{2}$ Chimet S.p.A., Arezzo, Italy \\ ${ }^{3}$ Mining and Metallurgy Institute Bor, Bor, Serbia \\ ${ }^{4}$ University of Belgrade, Faculty of Technology and Metallurgy, Belgrade, Serbia
}

Received 15.03.2020

Accepted 10.06.2020

\begin{abstract}
Silver nitrate in the solution was reduced in the presence of the dispersants by ascorbic acid, and silver particles were generated. The main goal was to examine the influence of different dispersants. The purpose was to improve the production process of the micro-sized silver powder for thick film silver pastes for applications in the photovoltaic sector and the printed electronics. Relatively high concentrations of the reagents were used to achieve a high yield of silver particles. It was a strict request for highly economic production. This paper shows the possibilities for future large-scale synthesis and potential industrial production. The particles were analyzed by the X-ray diffraction (XRD), scanning electron microscopy (SEM), and laser diffraction particle size analyzer.
\end{abstract} film.

Keywords: chemical reduction; submicrometer particles; silver powder; thick

\section{Introduction}

Silver is used extensively through history as precious metal value, for coins and art, and in the modern times in numerous industrial and commercial applications. It has notable characteristics such as the highest electrical and thermal conductivity of all metals and optical reflectivity near the best in infrared and most of the visible spectrum [1]. It is used for soldering, brazing, jewelry, and dental alloys and additionally for electrical

*Corresponding author: Stevan Dimitrijević, stevad@gmail.com 
contacts, and many applications in optics, electronics industry, energy sector, and medicine [2-5].

Nanoparticles (NPs) have attracted a lot of attention recently due to their exceptional characteristics. These are the particles with the dimensions in the range from $1 \mathrm{~nm}$ to $100 \mathrm{~nm}$. Their properties are related to very high surface to volume ratio and quantum size effects. For nanoparticle synthesis, the most used pure metals are copper, silver, and precious metals (gold, platinum, and palladium) [6-8], with silver being the dominant one [9], due to their general properties, as well as chemical stability, ease of obtaining, and favorably priced compared with others [10]. For some purposes, the benefit of the unique properties of AgNPs has been exploited for nanocomposite powders production based on mixed metals or their oxides [11]. As a result, AgNPs and colloidal silver are widely used in the high-tech chemical industry (catalysis, sensors, water treatment) [12-15], physic (photonics, optics) [16], electronics industry, renewable energy production and storage (photovoltaic solar cells, biofuels, lithium batteries) [1720], biotechnology (biosensing, botanics, advanced agriculture, pest control) [21-25], medicine and biomedical sciences, and pharmaceutical industry [26-29].

This variety of applications had led to a large number of methods for AgNPs synthesis. High requirements for each of them often include the strictly defined properties of the particles. Thus every of the method should be controlled in every detail. The synthesis techniques are numerous, but the most prominent are chemical reduction in the aqueous and non-aqueous solutions (including use of autoclave), use of microemulsions, thermal decomposition of silver compounds, radiation-assisted (gamma-ray, laser, microwave) processes, electrochemical, photochemical and sonochemical reduction, template method, and biosynthesis [30-35]. The prevalence of environmentally friendly technologies, among all mentioned is high [36].

Along with the AgNPs, the ultrafine metallic powders (near $1 \mu \mathrm{m}$ of average size) are commonly used in electrically conductive pastes, solid oxide fuel cells, and chemical catalysts, etc [37]. Wet-chemical methods are commonly used for the preparation of the micro-sized spherical Ag powders. However, methods for this purpose are not well developed [38], as most of them focused on the synthesis of nano-Ag particles. Only a few teams reported their research about these topics. Consequently, but unexpectedly, obtaining the powder with a narrow range of size distribution around and bellow one micrometer (500-1000 nm) could be an even harder task [39] compared to the nano-sized powder. Controlled aggregation of nanoparticles is the usual route for the formation of uniform spherical aggregates, and the larger sizes are thus more challenged to obtain [4043].

This paper is sequent to the previous researches [44-45] and is focused on obtaining micron- or sub-micron sized near-spherical silver particles, with the narrow size distribution, in the aim to use them in the production of silver pastes for thick films applied in solar cells.

\section{Experimental}

The following chemicals were used for silver solution preparation and its reduction from the solution: silver nitrate (crystal extra pure, $\geq 99.0 \%$, Ag content min. $63.5 \%$; Chimet S.p.A., Italy), ascorbic acid (analytical grade; Merck, Germany), polyvinylpyrrolidone (PVP K-30) (pharmaceutical grade; Ashland, Nederland), gelatin (pharmaceutical grade; Institute Torlak, Serbia). Additionally, citric acid (pro analysis, 
99.5\% ; Sigma-Aldrich, Germany) and sodium hydroxide (for analysis, $\geq 99.0 \%$; Merck, Germany) as $\mathrm{pH}$ regulators and absolute ethanol (pro analysis; Zorka, Serbia) for silver powder rinsing were used. Double distilled water, with conductivity lower than $1 \mu \mathrm{S} / \mathrm{cm}$, was used in all experiments.

A typical procedure was as follows; two solutions were made separately, the first one (solution 1) was the solution of $\mathrm{AgNO}_{3}$, and the second one (solution 2) was the solution of ascorbic acid (AA). The dispersant was divided into both solutions in equal volumes. A volume of $300 \mathrm{ml}$ of both solutions was used to obtain nearly $600 \mathrm{ml}$ of total solution in the laboratory glass of $1000 \mathrm{ml}$. Solution 1 was added to solution 2 with continuous stirring. Two magnetic stirrers were used for the dissolution of both reagents simultaneously. During the synthesis, a stirring rate of $300 \mathrm{~min}^{-1}$ was used, which was near the maximum for the laminar flow in the system. The temperature for the synthesis was $45 \pm 1{ }^{\circ} \mathrm{C}$. In the experiments with the additional use of surfactants, the volume of both starting solutions was decreased by $10 \%$ (to $270 \mathrm{ml}$ ). The missing volume of $60 \mathrm{ml}$ represents the solution with dissolved surfactant (solution 3), which was added to solution 2 at the start of the synthesis. The $\mathrm{pH}$ value of the ascorbic acid solution was typically 2.25 , and it was adjusted to $\mathrm{pH}=3$ by a few droplets of $10 \% \mathrm{NaOH}$ solution. That solution was used for experiments without $\mathrm{pH}$ corrections for the system. Without $\mathrm{pH}$ intervention, the total $\mathrm{pH}$ of the system was nearly 3.5 , and it was just adjusted to the precise value. If there is no indication about the $\mathrm{pH}$ of the synthesis, $\mathrm{pH}=3.5$ was the value. Higher $\mathrm{pH}$ values were obtained by the use of $10 \% \mathrm{NaOH}$. Citric acid has been used only for finetuning of the $\mathrm{pH}$. The exact $\mathrm{pH}$ values in the experiments are noted in the further text.

Scanning electron microscope (SEM) images and electron diffraction spectroscopy (EDS) analysis were taken on a JSM IT 300LV (JEOL, Japan) operated at $20 \mathrm{keV}$ and an $\mathrm{X}$-max (Oxford Instruments, UK), respectively. The X-ray diffraction (XRD) patterns were performed on an Explorer X-ray diffractometer (GNR Analytical Instruments, Italy) using $\mathrm{Cu} \mathrm{K \alpha} \alpha_{1 / 2}$ radiation, $\lambda=0.154 \mathrm{~nm}$, operated at $40 \mathrm{kV}$ and $30 \mathrm{~mA}$. For the X-ray analysis, the software PDXL 2 Version 2.4.2.0. were used. The resulting diffractograms are compared to the data from the database ICDD (PDF-2 Release 2015 RDB). The particle size distribution was measured and analyzed using a Malvern Mastersizer 2000 with 2000S Hydro liquid sampler and Mastersizer 2000 software Version 5.1 (Malvern Instruments, UK). The $\mathrm{pH}$ values of the solutions were measured by InoLab $\mathrm{pH} 720$ Laboratory Meter (WTW, Germany). The measurement of the solutions containing the silver ions was performed with the use of salt bridge containing potassium nitrate.

\section{Results and discussion}

Use of PVP as the dispersant

The starting point was a standard hydrometallurgical procedure where Ag+ ions were reduced by ascorbic acid in the presence of the PVP as the dispersant. A high concentration of reagents were used, in the aim to get a maximal yield of the silver powder, which is the ultimate requirement from the industry. When the silver nitrate/PVP solution was added slowly into the ascorbic acid/PVP solution, an induction period lasting several minutes preceded the formation of colloidal dispersion. The nucleation event was not clearly marked, but an increase in the turbidity of the dispersion indicates it. The start of particle growth was associated with color change after about 45 minutes. The synthesis 
was prolonged by 15 minutes and then finished by filtering the solution. The broad size distribution and the large average size of the particles are shown in Figure 1.

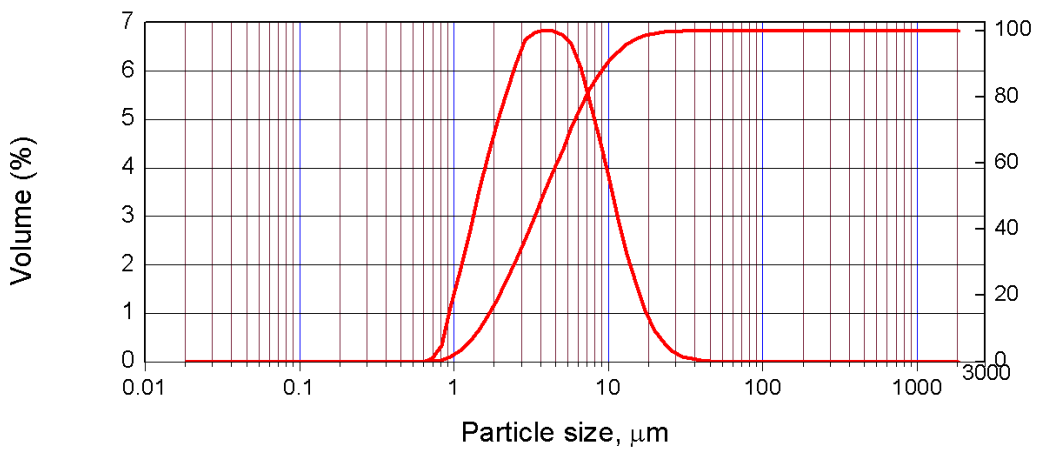

Fig. 1. Typical particle size distribution for the silver powder obtained by reduction of $\mathrm{AgNO}_{3}(45 \mathrm{~g} / \mathrm{l})$ by $\mathrm{AA}(30 \mathrm{~g} / \mathrm{l})$ in the presence of PVP $(10 \mathrm{~g} / \mathrm{l})$ and without $\mathrm{pH}$ adjustment

Although 100\% yield was achieved, particle sizes were far from the aim (about 1 $\mu \mathrm{m}$ on average, and less than $3 \mu \mathrm{m}$ for the most (at least $90 \%$, preferably $95 \%$ ) of the particles. Most of the particles were between 1.5 and $7.5 \mu \mathrm{m}$. Additionally, a wide distribution is clear from Figure 1. This was not a satisfying result, but it would be used for comparison with other procedures. Additional analysis of the size distribution is given in Table 1.

Table 1. Characteristics sizes from the cumulative particle size distribution curve in Figure 1

\begin{tabular}{lllll}
\hline Specific surface area, $\mathrm{m}^{2} / \mathrm{g}$ & $\mathrm{D} 10, \mu \mathrm{m}$ & $\mathrm{D} 50, \mu \mathrm{m}$ & $\mathrm{D} 90, \mu \mathrm{m}$ & $80.30 \%$ \\
\hline 0.22 & 1.468 & 3.523 & 9.159 & $-6.854 \mu \mathrm{m}$ \\
\hline
\end{tabular}

It should be noted that a significant share $(8.31 \%)$ is even above $10 \mu \mathrm{m}$. Even the average size of $\sim 3.5 \mu \mathrm{m}$ could be very useful for many other applications, the use is limited by D90 value and the distribution that extents over a full order of the magnitude, roughly from 1 to $20 \mu \mathrm{m}$ (for more than $98 \%$ of the particles).

Improvement could be obtained by the reduction of the reagent concentrations. In this research, it was reduced on two thirds, except PVP, which had to be on the same level (concentration was half of that, at the start, because it was divided between solutions 1 and 2). In the series of experiments, different synthesis time was used. In an experiment, the time of the reaction has been shortened to $30 \mathrm{~min}$ and with filtering only 5 min after. It was the attempt with the best results when PVP was dispersant since further time reduction was not beneficial. The influence of $\mathrm{pH}$ value is very significant, as is wellknown from the literature [31, 46] and it was shown in our previous paper [44]. In the experiments with PVP, we concluded that the $\mathrm{pH}$ around six and above contributed stronger reduction and more favorable nucleation. However, high $\mathrm{pH}$ values impact 
ascorbic acid stability, which is lower than at $\mathrm{pH}=4$ or less. A good compromise was synthesis at $\mathrm{pH}=7$, and the results are shown in Figure 2.

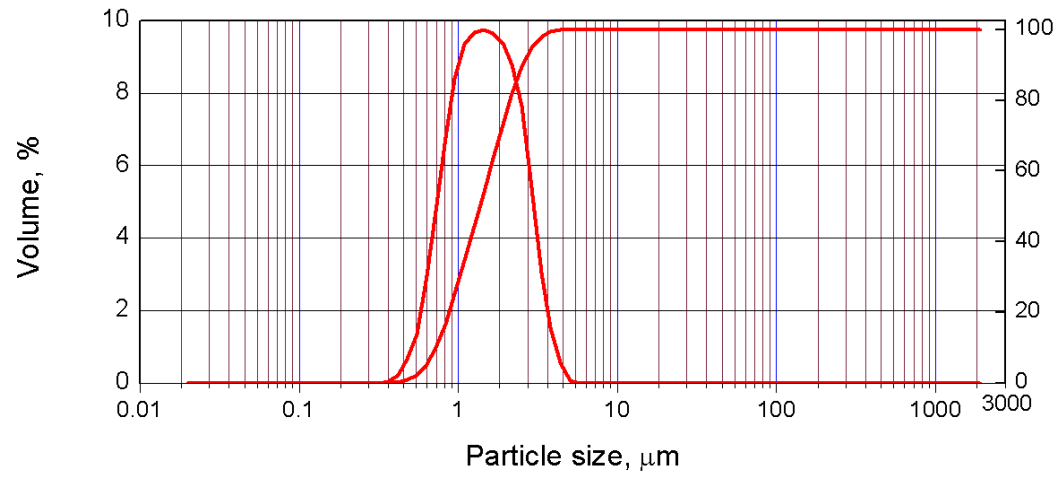

Fig. 2. Particle size distribution for the silver powder obtained by reduction of $\mathrm{AgNO}_{3}(30 \mathrm{~g} / \mathrm{l})$ by $\mathrm{AA}(20 \mathrm{~g} / \mathrm{l})$ in the presence of $\mathrm{PVP}(10 \mathrm{~g} / \mathrm{l})$ at $\mathrm{pH}=7$.

Much narrower size distribution can be observed in Figure 2 compared to Figure 1. The average size of the particles was around $1.2 \mu \mathrm{m}$ and $1.4 \mu \mathrm{m}$, depending on whether the surface mean or the volume mean diameter was calculated. The D50 value was 1.335 $\mu \mathrm{m}$, which is more than 2.5 times smaller than in the previous methodology. Values for D10 and D90 were $0.706 \mu \mathrm{m}$ and $2.550 \mu \mathrm{m}$, respectively. Finally, the surface area was $4.9 \mathrm{~m}^{2}$, which was a great result.

The SEM image (Fig. 3) confirms the granulometric analysis but reveals the origin of the final particles. At the start of the process, nanoparticles are formed, but during the time, they become larger due to agglomeration and aggregation. Numerous secondary particles with size ranged from 100 to $300 \mathrm{~nm}$ are present in the micrograph. They have formed smaller aggregates, which are rigidly jointed, with a size of 500 to $1500 \mathrm{~nm}$. The smaller of these particles $(\sim 500 \mathrm{~nm})$ are polyhedral, and the larger ones (nearly or slightly above $1000 \mathrm{~nm}$ ) are nearly spherical. Large agglomerates were mostly made from loosely bonded nanoparticles and had irregular shapes, usually about $1 \mu \mathrm{m}$ wide and 2 to $3 \mu \mathrm{m}$ long. They can be partially disintegrated by micro sieving. 


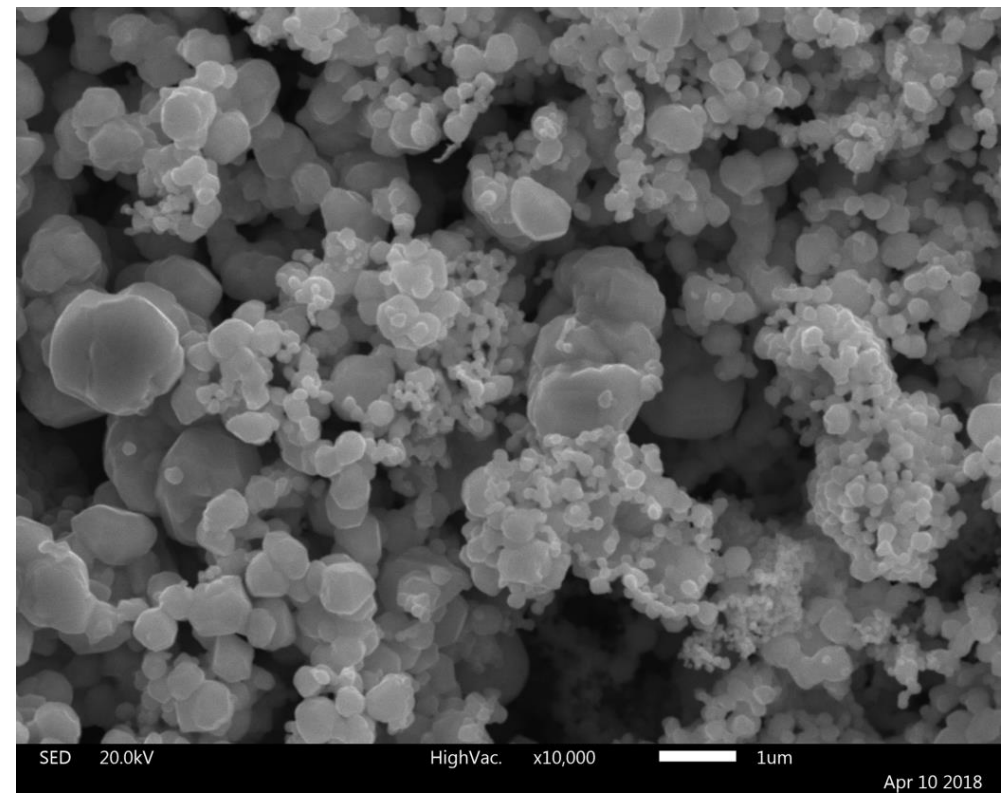

Fig. 3. The silver powder obtained by the use of $P V P$ at $p H=7$, with the concentrations of reagents as in Figure 2.

The yield was nearly $100 \%(98.4 \%)$, with just a little fraction of small colloidal particles. Silver ions were not found in the solution. The method could be further improved by lowering the reagent concentration and raising the concentration of PVP, but it results in low yield (under $90 \%$ for just $20 \%$ lower concentration of reagents) and high expenses of the process, which is unsatisfactory for the industry. Additionally, it is the right method for the synthesis of the nanoparticles, but sub-micro sized are difficult to obtain with the narrow size distribution.

\section{Use of gelatin as a dispersant}

The procedure was the same as previously. The concentrations of the reagents were $\mathrm{c}\left(\mathrm{AgNO}_{3}\right)=45 \mathrm{~g} / \mathrm{l}$ and $\mathrm{c}(\mathrm{AA})=30 \mathrm{~g} / \mathrm{l}$. Gelatin mass ratio vs. $\mathrm{AgNO}_{3}$ was 0.024 . Since $\mathrm{pH}$ was not regulated, with the only correction to $\mathrm{pH}=3$ for the AA solution, the final solution had $\mathrm{pH}$ 3.4-3.6, where ascorbic acid is very stable. The smaller portion of the gelatine has been added to the ascorbic acid solution (40\% of all gelatin). The higher concentration was in silver nitrate solution, $60 \%$ of the gelatin. Gelatin was dispersed in water with room temperature in the first 15 minutes, before the addition of other components. After that, the dispersion was heated to $50{ }^{\circ} \mathrm{C}$. For the next $45 \mathrm{~min}$, it has been mixed at that temperature. SEM analysis of synthesized Ag powder is presented in figure 4. 


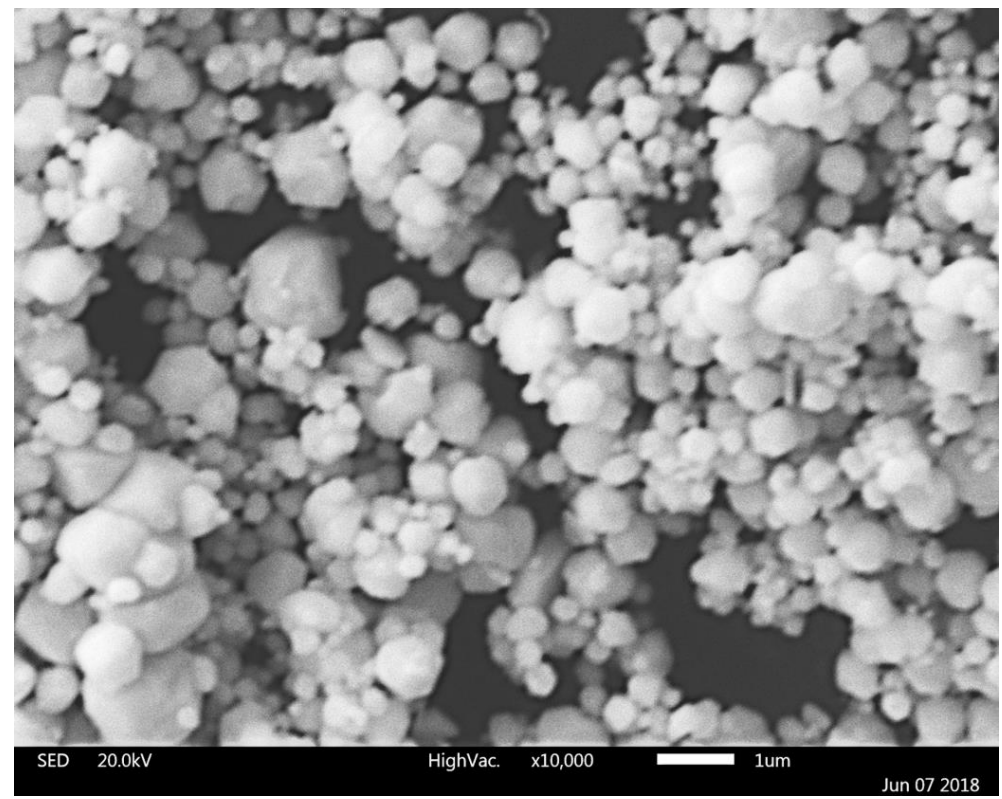

Fig. 4. Silver powder obtained by the use of gelatin, $2.4 \mathrm{wt} . \%$ of the $\mathrm{AgNO}_{3}$, at $\mathrm{pH}=3.5$.

Figure 4 shows that most of the particles are under $1 \mu \mathrm{m}$, although there are some agglomerates with approximately $2 \mu \mathrm{m}$ in length. The big share (portion) of the particles is smaller than 500 or even $300 \mathrm{~nm}$. Even particles with around $0.2 \mu \mathrm{m}$ are clearly visible.

Typical particles, in the micrograph, are approximately 650 to $1250 \mathrm{~nm}$. The full range of dimensions of the silver particles could be estimated from 300 to $1500 \mathrm{~nm}$ in size. Some of the nanoparticles (under $100 \mathrm{~nm}$ ) are also visible, although particles smaller than $200 \mathrm{~nm}$ are rare. Several clusters (agglomerates) indicate that some better flushing of the powder is needed. It also implies that micro-sieving is needed (not applied here), probably down to $5 \mu \mathrm{m}$, or at least $10 \mu \mathrm{m}$. Although agglomerated particles are smaller, the vibrations should lead to their disintegration, to some extent at least. It is also an indication that the time of the reaction should be even shorter, though it means lower yield, as experimentally confirmed. The reaction times of 25 and 20 minutes were tested with marginal improvements and yields of $91.3 \%$ and $87.6 \%$, respectively. Most of the particles are near-spherical, although agglomerates are polyhedral or even pyramidal (in the lower-left corner). This should be considered a good result. Particle size distribution for the synthesis is shown in Fig. 5. 


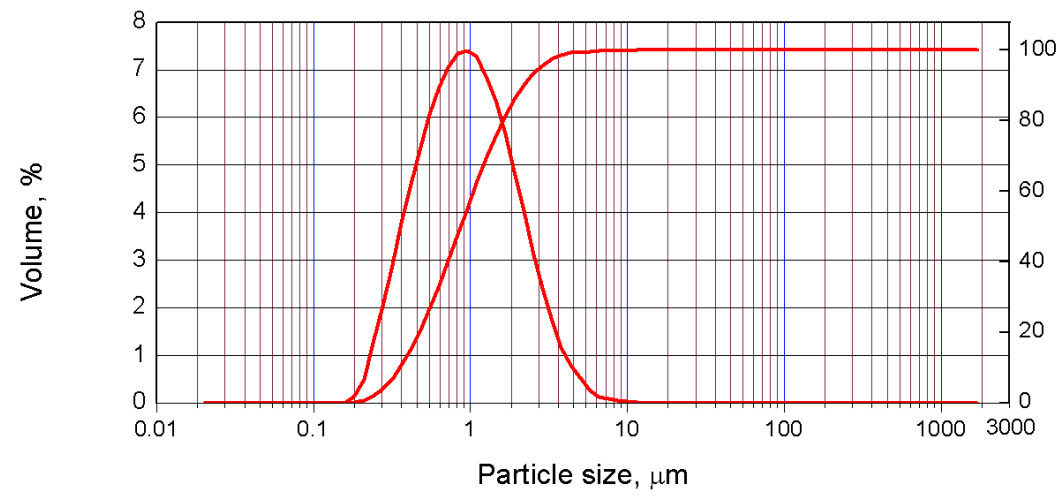

Fig. 5. Granulometric composition of the powder obtained by use of gelatin with a higher concentration of reactants and the ratio gelatin vs. silver nitrate of 0.024 .

Granulometric analysis confirms the finding from the SEM micrographs. Figure 5 shows a wide particle size distribution. It was similar, although a little bit narrower than in the case of PVP with high concentrations of reactants. Improved PVP conditions (Figure 2) have given much better results.

Despite D50 was under one micrometer $(871 \mathrm{~nm})$, and the result for D90 $(2.177 \mu \mathrm{m}), 2.5 \%$ of particles larger than $3.311 \mu \mathrm{m}$ confirms the agglomeration, visible from the SEM images and indicated by the shape of the curve. Some large aggregates are also present, but only $0.1 \%$ of the particles were larger than $7.5 \mu \mathrm{m}$. The yield was $94.57 \%$.

Similar to the use of PVP, improvement for the method was performed by the change of parameters. The concentrations of the reagents were reduced on two thirds. However, the concentration of the gelatin remained the same. Consequently, the ratio between gelatin and silver nitrate was 0.036 . It was $50 \%$ higher than in the previous experiment. The $\mathrm{pH}$ value was increased to seven, exactly as in the case of PVP. The rest of the procedure was identical to the previous one. Much smaller particles than in the previous case, are visible in Figure 6. A better particle size distribution is also clear from the same micrograph. 


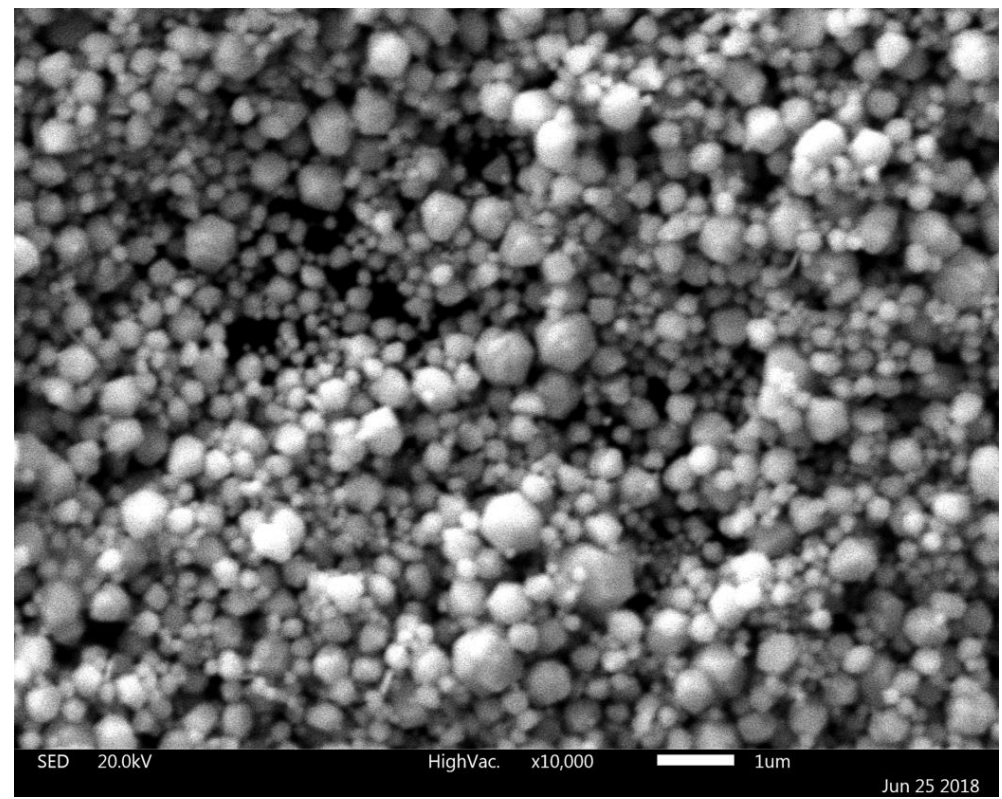

Fig. 6. Silver powder obtained by the use of gelatin, $3.6 \mathrm{wt} . \%$ of the silver nitrate, at $p H=7$.

Smaller particles are near-spherical, which was the aim of the research. It can be estimated that their size is far below $1 \mu \mathrm{m}$, and a large proportion of those is about 500 $\mathrm{nm}$. The aggregates are a little bit larger than a micrometer, some of them were still spherical, but most of them were polyhedral. It was almost a rule that the smaller particles were more spherical. A large number of particles have dimensions from 150 to $300 \mathrm{~nm}$, and the typical particles are from 400 to $900 \mathrm{~nm}$. Rare agglomerates (lower left in Figure 6) are about $2 \mu \mathrm{m}$ in size.

More precise particle size distribution is shown in Figure 7.

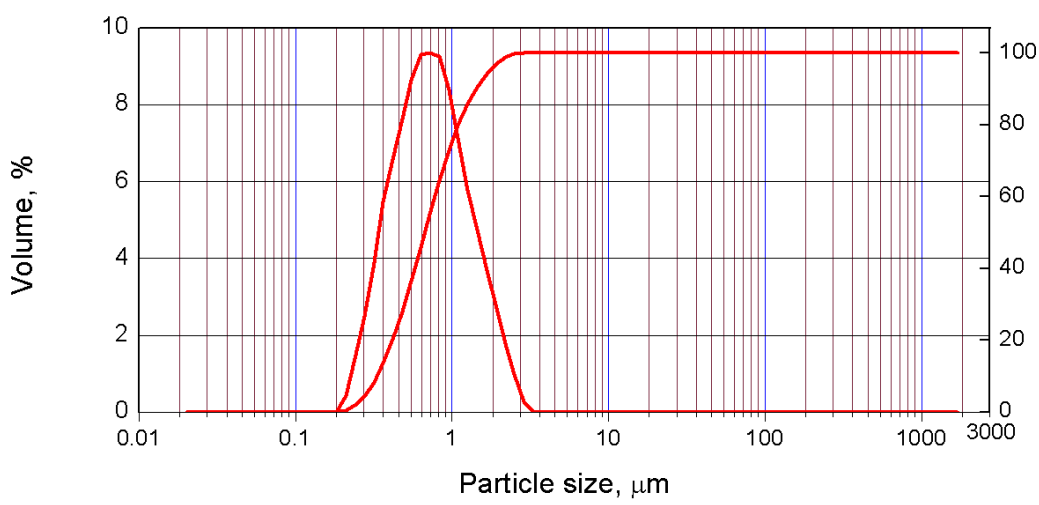

Fig. 7. Granulometric composition of the powder obtained by use of gelatin with a lower concentration of reactants and the ratio gelatin vs. silver nitrate of $3.6 \%$. 
Although D10 was similar to the previous (333 nm vs. $356 \mathrm{~nm}$ ) smaller average particle size, as well as narrower distribution is clear from Figure 7. Values for D50 and D90 were $672 \mathrm{~nm}$ and $1426 \mathrm{~nm}$, respectively. More than $99 \%$ of the particles were smaller than $2.276 \mathrm{~mm}$, and the $+2.884 \mathrm{~mm}$ was $0.0 \%$. Finally, about three-quarters of the particles $(75.10 \%)$ were under the micrometer. Due to that, we could doubtless say that method for sub-micro sized silver particles was realized.

A drawback of the synthesis under these parameters was the relatively low yield, just above $80 \%(82.37 \%)$. The reason for this was a very stable colloidal solution. Under normal gravitation, this solution was stable for more than a week. Under centrifuge, it was settled, and analysis has shown that the powder consisted mainly ( $88 \%)$ of the nanoparticles of non-uniform size. The size of these colloidal particles has been ranging from 30 to $120 \mathrm{~nm}$. The particle size distribution is shown in Figure 8.

Although the stable colloidal solution is not preferred in this kind of synthesis, it can be benefited for the simultaneous synthesis of the nano- and sub-micro sized silver particles.

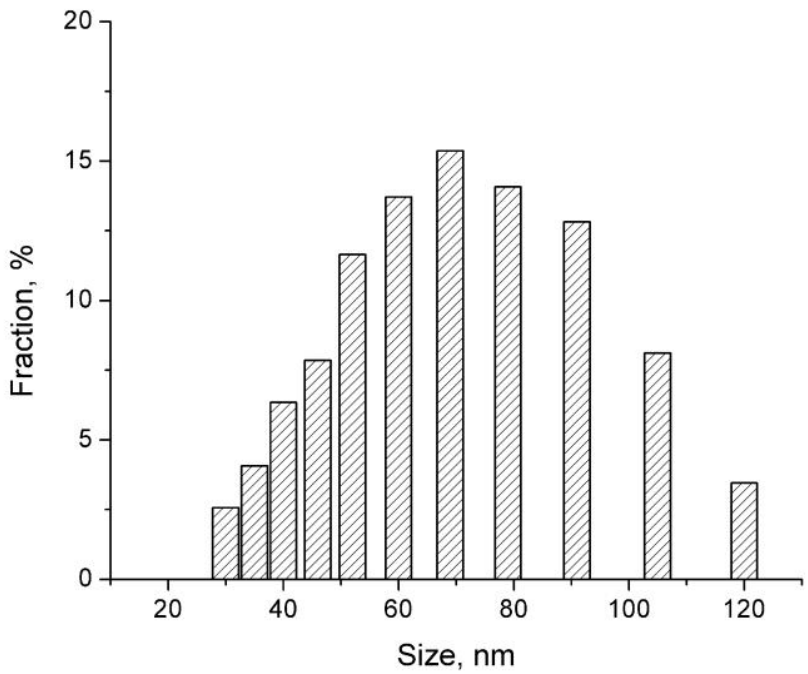

Fig. 8. Size distributions of colloidal silver particles

An additional problem with the procedure was the harder wash-up of the powder compared with the procedure where PVP was used. The more ethyl alcohol has been required to obtain a non-sticky powder.

EDS analysis has shown $100.00 \%$ or minimum $99.99 \%$ of silver, for all samples above. It has been expected since EDS results showed only a percentage in the metallic phase. A few tens of a percent lower concentrations of silver than full $100 \%$ could be expected, especially in the case of gelatin as the dispersant.

Finally, XRD analysis of the obtained powders has shown almost identical results for the use of PVP and gelatin. 

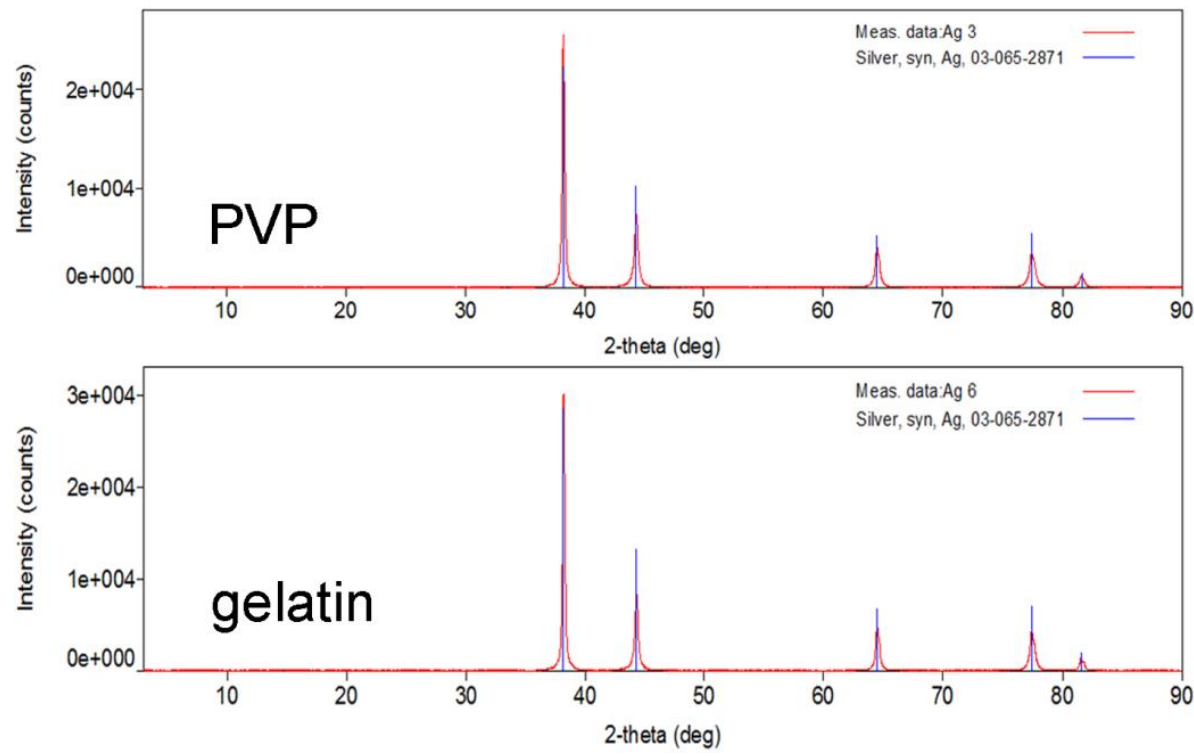

Fig. 9. XRD pattern of silver powders; synthesis with PVP and Gelatin.

The results have shown in both cases that the diffraction peaks position and their intensity matching with diffraction data from the base. Five prominent peaks were apparent in the patterns, which are characteristics of fcc silver. These five peaks sequentially correspond to the (111), (200), (220), (311), and (222) planes. The diffractograms did not contain peaks of any impurity phases. The sharp diffraction peaks indicate a high degree of crystallization.

\section{Conclusions}

This study has presented the procedure for the production of micro and sub-micro sized silver particles by chemical reduction method. Reduction agent was always ascorbic acid but two types of dispersant were used. One of the main requirements for the synthesis was the utility of environmentally acceptable products.

The synthesis that used PVP has not fully satisfied the production of the $\mathrm{Ag}$ particles with an average size of one micrometer. With the high concentration of reagents, a wide size distribution was obtained with the average particle size above $3 \mu \mathrm{m}$. However, with the use of one third lower concentrations of the reagents and the same concentration of PVP, the method has shown the possibility to obtain particle size below $1.5 \mu \mathrm{m}$ with quite a narrow size distribution. The results indicate that the method could be applied for the synthesis of the silver nanoparticles, but with lower yield and much higher costs.

The method with the use of gelatin has shown a good result even with the high concentrations of reagents and the amount of dispersant of $2.4 \%$ vs. $\mathrm{AgNO}_{3}$. Nevertheless, a wide size distribution has shown that the combination of the parameters was not optimal. When concentrations of the reagents were reduced, with the same addition of gelatin, a quite improvement was obtained. All the particles were under $3 \mu \mathrm{m}$, D90 was lower than $1.5 \mu \mathrm{m}$, and the D50 was $672 \mathrm{~nm}$. A drawback of the gelatin was the harder rinsing of the powder. 
The SEM micrographs have confirmed the findings of the granulometric analysis. The XRD analysis has shown well crystallization of silver particles for both used dispersant. In the experiment with the best result, the lowest yield was achieved. It was due to the remaining silver colloids in the solution, sized from 30 to $120 \mathrm{~nm}$.

The use of synthesis with lower concentrations of reagents and the use of PVP with the investigated parameters can be directly implemented in the industry for the production of the silver powder with average particle sizes between one and two micrometers. The same concentrations of the reagents and the lower concentration of the gelatin can also be directly implemented in the industry for the ultrafine silver powder with an average particle size of approximately one micrometer.

\section{Acknowledgments}

This work was supported by the Ministry of Education, Science and Technological Development of the Republic of Serbia (Contract No. 451-03-68/2020-14/200135). This article is based upon work from COST Action CA19140, supported by COST. The paper is also part of the activity in the scientific project between IC TMF Belgrade, Serbia, and Chimet Company, Arezzo, Italy.

\section{References}

[1] W.M. Haynes, David R. Lide, CRC Handbook of Chemistry and Physics, 95st ed., Internet Version, CRC Press, Boca Raton, FL., 2014, 4-29.

[2] J.C. Lin, C.Y. Wang: Mater Chem Phys, 45 (1996) 136-144.

[3] J.T. Tsai, S.T. Lin: J Alloys Comp, 548 (2013) 105-109.

[4] M. Ardestani: Int J Mater Res, 106 (2015) 1294-1297.

[5] M. Murphy, K. Ting, X. Zhang, C. Soo, Z. Zheng: J Nanomater, 2015 (2015) 696918, 1-12.

[6] H. Luo, Y. Zhao, L. Sun: Mater Res Bull, 46 (2011) 1151-1155.

[7] W. Zhang, X. Qiao, J. Chen: J Mater Sci Eng B, 142 (2007) 1-15.

[8] R. McGrath: Platinum Met Rev, 54 (2010) 122-124.

[9] F. Begum, S.A. Jahan, M.Y.A. Mollah, M.M. Rahman, M.A.B.H. Susan: J Sci Res (Rajshahi, Bangladesh), 9 (2017) 431-447.

[10] J.T. Luw: Phys Chem Solids, 62 (2001) 1599-1612.

[11] Z. Anđič, M. Korać, M. Tasić, K. Raić, Ž. Kamberović: Kovove Mater, 44 (2006) 145-150.

[12] Z.J. Jiang, C.Y. Liu, L.W. Sun: J Phys Chem B 109 (2005) 1730-1735.

[13] D. Vilela, M.C. González, A. Escarpa: Anal Chim Acta, 751 (2012) 24-43.

[14] P.Vasileva, B. Donkova, I. Karadjova, C. Dushkin: Colloids Surf, A, 382 (2011) 203-210.

[15] Y. Xia, Xi. Jiang, J. Zhang, M. Lin, X. Tang, J. Zhang, H. Liu: Appl Surf Sci, 396 (2017) 1760-1764.

[16] I. Shutsko, C.M. Böttge, J. von Bargen, A. Henkel, M. Meudt, P. Görrn: Nanophotonics, 8 (2019) 1457-1464.

[17] Z. Zhang, W. Zhu: J Alloys Compd, 649 (2015) 687-693.

[18] Q. Che, H. Yang, L. Lu, Y. Wang: J Mater Sci: Mater Electron, Mater Electron, 24 (2013) 524-528.

[19] J. Mo, B.I. Stefanov, T.H.M. Lau, T. Chen, S. Wu, Z. Wang, X.Q. Gong,I. Wilkinson, G. Schmid, S.C.E. Tsang: ACS Appl. Energy Mater, 2 (2019) 1221 1228 . 
[20] [Y. Kong, Z. Ma, D. Zheng, C. Yang, J. Zheng, G. He, J. Nan: Mater Lett, 251 (2019) 118-121.

[21] S.A. Razack, S. Duraiarasan, V. Mani: Biotechnol Rep, 11 (2016) 70-76.

[22] S. Schultz, D.R. Smith, J.J. Mock, D.A. Schultz: Proc Natl Acad Sci U.S.A., 97 (2000) 996-1001.

[23] R. Nair, S.H. Varghese, B.G. Nair, T. Maekawa, Y. Yoshida, D.S. Kumar: Plant Sci, 179 (2010) 154-163.

[24] M. Rouhani, M.A. Samih, S. Kalantari: Chil J Agr Res 72 (2012) 590-594.

[25] A. Narayanan, P. Sharma, B.M. Moudgil: KONA Powder Part J, 30 (2013) 221235.

[26] A. Ravindran, P. Chandran, S.S. Khan: Colloids Surf, B, 105 (2013) 342-352.

[27] A.S. Maryan, M. Gorji: Bulg Chem Commun, 48D (2016) 151-155.

[28] Z. Tavaf, M. Tabatabaei, A. Khalafi-Nezhad, F. Panahi: Eur J Integr Med, 12 (2017) 163-171.

[29] P. Mathur, S. Jha, S. Ramteke, N.K. Jain: Artif Cells, Nanomed, Biotechnol, 46 (2018) 115-126.

[30] S.K. Srikar, D.D. Giri, D.B. Pal, P.K. Mishra, S.N. Upadhyay: Green Sustain Chem, 6 (2016) 34-56.

[31] D. Andreescu, C. Eastman, K. Balantrapu, D.V. Goia: J Mater Res, 22 (2007) 2488-2496.

[32] Z. Khan, S.A. Al-Thabaiti, A.Y. Obaid, A.O. Al-Youbi: Colloids Surf, B, 82 (2011) 513-517.

[33] W.Z. Zhang, X.L. Qiao, J.G. Chen: Chem Phys, 300 (2006) 495-500.

[34] A. Henglein: Langmuir 17 (2001) 2329-2333.

[35] R. Singaravelan, S.B.S. Alwar: Appl Nanosci, 5 (2015) 983-991.

[36] M. Ovais, A. T. Khalil, M. Ayaz, I. Ahmad, S.K. Nethi, S. Mukherjee: Int J Mol Sci, 19 (2018) 4100, 1-20.

[37] K. Sannohe, T. Ma, S. Hayase: Adv Powder Technol, 30 (2019) 3088-3098.

[38] B. An, X.-h. Cai, F.-s. Wu, Y.-p. Wu: Trans Nonferrous Met Soc China, 20 (2010) 1550-1554.

[39] S. Xuping, D. Shaojun, E. Wang: J Colloid Interface Sci, 290 (2005) 130-133.

[40] K.P. Velikov, G.E. Zegers, A. van Blaaderen: Langmuir, 19 (2003) 1384-1389.

[41] I. Halaciuga, D.V. Goia: J Mater Res, 23 (2008) 1776-1784.

[42] S.B. Rane, V. Deshapande, T. Seth, G.J. Phatak, D.P. Amalnerkar, B.K. Das: Powder Metall Met Ceram, 43 (2004) 437-442.

[43] N. Moudir, N. Moulaï-Mostefa, Y. Boukennous: Chem Ind Chem Eng Q, 22 (2016) 227-234.

[44] S.P. Dimitrijević, Ž.J. Kamberović, M.S. Korać, Z.M. Anđić, S.B. Dimitrijević, N.S. Vuković: Metall Mater Eng, 20 (2014) 73-87.

[45] S.P. Dimitrijević, Z. Anđić, Ž. Kamberović, S.B. Dimitrijević, N. Vuković: Bulg Chem Commun, 46 (2014) 814-824.

[46] Z. Liu, X. Liang, H. Wang: Adv Powder Technol, 23 (2012) 250-255.

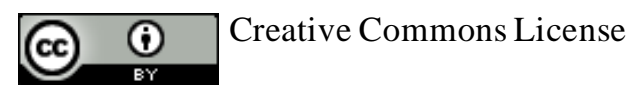

This work is licensed under a Creative Commons Attribution 4.0 International License. 